\title{
Desempenho de Cordeiros das Raças Bergamácia e Santa Inês, Terminados em Confinamento, Recebendo Dejetos de Suínos como Parte da Dieta
}

\author{
Marcus Vinícius Morais de Oliveiraㄹ, Juan Ramón Olalquiara Pérez², Iraides Ferreira Furusho \\ Garcia $^{3}$, Alessandra Rodrigues Vieira Martins ${ }^{4}$
}

\begin{abstract}
RESUMO - Foram confinados, individualmente 33 cordeiros das raças Bergamácia e Santa Inês, por um período de 75 dias, com o intuito de avaliar a influência da raça e a viabilidade de utilizar dejetos de suínos como parte da dieta, sobre o consumo e desempenho de cordeiros terminados em confinamento. Utilizaram-se dois tipos de dejetos: o Bijú (Dejeto obtido através da raspagem e varredura do piso das baias de crescimento e terminação) e o Dejeto Peneirado Seco - DPS (Dejeto obtido através da peneiração da parte sólida do material contido na lâmina d’água e na água da lavagem das baias). Os tratamentos foram: T1-Controle; T2- Dieta com 24 \% de Bijú; e T3- Dieta com $24 \%$ de DPS. O ganho de peso (GP) e conversão alimentar (CA) foram afetados negativamente com o uso de dejetos de suínos, todavia o consumo proteína bruta (PB) e cálcio (Ca) não foi influenciado. Houve maior consumo de fósforo (P) nas dietas contendo dejetos, sendo o consumo de fibra em detergente neutro (FDN) e extrato etéreo (EE) variável. Entre as rações que continham dejetos não foram verificadas diferenças sobre os consumos de MS, PB, Ca e P e sobre o GP. Os cordeiros da raça Bergamácia apresentaram maior GP que os cordeiros da raça Santa Inês.
\end{abstract}

Palavras-chave: nutrição, ovinos, resíduos, suínos, crescimento

\section{Performance of Bergamácia and Santa Inês Lambs, Finished in Fedlot, Receiving Swine Wastes as Part of Diet}

\begin{abstract}
Thirty three lambs of Bergamácia and Santa Inês the breeds were individually confined for a period of 75 days with the objective to evaluate the influence of breed and the viability of the use of swine wastes as part of the diet on the intake and performance of lambs. Two types of wastes were used: Bijú (Wastes obtained through the scratching and sweeping of the floor of the growth and termination stalls) and the Dry Sifted Wastes - DSW (Wastes obtained through the sifting of the solid part of the material contained in the of water sheet of the stalls and in the water of washing of the stalls). The treatments were: T1- Control; T2- Diet with 24\% of Bijú; and T3- Diet with 24\% of DSW, dry matter base. There was influence of the rations $(\mathrm{P}<0.05)$ on the intake of neutral detergent fiber (NDF), ethereal extract (EE) and phosphorus (P); and also in the live weight gain (LWG) and in the alimentary conversion (AC). Among the diets with wastes it was not verified differences on the intake of DM, CP, Ca and P; and in LWG. The lambs of the Bergamácia breed showed a higher LWG than the Santa Inês lambs.
\end{abstract}

Key Words: nutrition, ovine, waste, swine, growth

\section{Introdução}

A maior concentração de rebanhos de ovinos no Brasil está localizada no Estado do Rio Grande do Sul, onde se considera a lã uma prioridade da exploração. No entanto, esta tradição vem se modificando significativamente nos últimos anos, com o incremento do rebanho nos estados do Paraná, Santa Catarina e São Paulo, que investem, em especial, nas raças especializadas em produção de carne. Esta mudança possivelmente foi estimulada, principalmente, pelo baixo preço da lã, pela crescente demanda de carnes alternativas do mercado consumidor e pela alta rentabilidade econômica que a exploração da ovinocultura proporciona ao criador. Desse modo, a expansão das raças de corte vem fazendo com que os ovinos adquiram importância cada vez maior como um produtores de carne (Martins, 1997).

A terminação de ovinos em confinamento é uma alternativa para intensificar a produção de carne, devido à maior rapidez com que os animais chegam ao ponto de abate e pela maior facilidade de controlar as verminoses. Todavia, este tipo de criação requer maior investimento no que se refere às instalações, alimentação e mão-de-obra. Uma das formas de viabilizar este sistema é a utilização de rações formu-

\footnotetext{
${ }^{1}$ Doutorando - Departamento de Zootecnia/UFV. E.mail: marcusvmo@terra.com.br

2 Departamento de Zootecnia/UFLA. E.mail: jroperez@ufla.br

${ }^{3}$ Departamento de Zootecnia - FAC -FAFEID. E.mail: ifurusho@citel1.com.br

${ }^{4}$ Mestre em Zootecnia.
} 
ladas com alimentos alternativos disponíveis em cada região (Confinamento, 1993). Uma boa opção é a utilização de dejetos de suínos, já que estes são produzidos em grandes quantidades na criação intensiva destes animais. Normalmente, os criadores de suínos têm sérios problemas com a eliminação dos dejetos, já que eles não são totalmente absorvidos na propriedade nem tratados de modo adequado, ocasionando assim uma poluição das aguas e prejudicando a sobrevivência da fauna e da flora da região. Portanto, a utilização destes dejetos também contribuirá com a preservação do meio ambiente (Oliveira, 1993).

A composição química dos dejetos de suínos é bastante variável e depende da alimentação fornecida aos suínos, da idade do animal, da quantidade de urina presente, da forma de coleta, do tipo de tratamento dado as fezes e do tempo de estocagem (Oliveira, 1994). De acordo com Hilliard et al. (1979), os teores de proteína bruta podem variar de 11,8 a 31,4\% e o extrato etéreo de 1,8 a 9,4\%. Os dejetos também são ricos em cálcio ( $3 \%$ na matéria seca), fósforo (2\% na matéria seca) e na maioria dos micro-minerais, já que 90\% destes podem ser excretados nas fezes (Henning e Flachowsky, 1982).

Deste modo, o uso de dejetos de suínos como alimento para cordeiros, poderá além de amenizar os problemas de poluição ambiental, também reduzir os custos da alimentação e viabilizar a terminação destes animais no sistema de confinamento. Assim, este trabalho teve como objetivo avaliar o efeito da inclusão de dejetos de suínos sobre o consumo e desempenho de cordeiros das raças Bergamácia e Santa Inês.

\section{Material e Métodos}

O experimento foi realizado nas instalações do setor de Ovinocultura do Departamento de Zootecnia da Universidade Federal de Lavras, na cidade de Lavras- MG. Foram utilizados 33 cordeiros, sendo 12 machos e 12 fêmeas da raça Santa Inês e 9 machos da raça Bergamácia, com idade média de 135 dias e peso vivo médio de $30 \mathrm{~kg}$. Todos os cordeiros foram vermifugados antes de iniciar o experimento; sendo estes mantidos confinados individualmente em gaiolas de estrutura metálica, providas de bebedouro e cocho para alimento e montadas em galpão de alvenaria coberto.

As dietas isoprotéicas, com 15\% de proteína bruta, eram fornecidas uma vez ao día a vontade, na forma de ração total, levando-se em conta a inclusão de $20 \%$ de feno de aveia, como volumoso e $24 \%$ de dejetos de suínos. Na Tabela 1, são apresentadas as composições químicas do feno de aveia e dos dejetos utilizados.

Os dois tipos de dejetos de suínos utilizados foram: 1- Bijú: obtido por meio da raspagem e varredura do piso das baias de crescimento e terminação de suínos, sendo este composto por fezes, urina, ração desperdiçada, pêlos e poeiras decorrentes do processo criatório. Depois de retirados do piso, os dejetos foram secos ao sol até um ponto em que pudessem ser moídos. 2 - Dejeto Peneirado Seco ao Sol (DPS): obtido por meio de um processo que envolveu a separação dos dejetos que estavam contidos na lâmina d’água e na água da lavagem das

Tabela 1 - Teores de matéria seca (MS), proteína bruta (PB), fibra em detergente neutro (FDN), fibra em detergente ácido (FDA), extrato etéreo (EE), matéria orgânica (MO), matéria mineral (MM), cálcio (Ca), fósforo $(P)$ e energia digestível (ED), do feno de aveia e dos dejetos de suínos

Table 1 - Chemical composition of the dry matter (DM), crude protein (CP), fiber in neutral detergent (NDF), fiber in acid detergent $(A D F)$, etherl extract $(E E)$, organic matter $(O M)$, mineral matter $(M M)$, calcium (Ca), phosphorus $(P)$ and digestible energy (DE), of the oat hay and of the swine wastes

\begin{tabular}{|c|c|c|c|c|c|c|c|c|c|c|}
\hline Item & $\begin{array}{c}\text { MS } \\
D M \\
\%\end{array}$ & $\begin{array}{l}\mathrm{PB} \\
C P\end{array}$ & $\begin{array}{l}\text { FDN } \\
N D F\end{array}$ & $\begin{array}{l}\text { FDA } \\
A D F\end{array}$ & $\begin{array}{c}\mathrm{EE} \\
\mathrm{EE} \\
\% \mathrm{MS} \\
\end{array}$ & $\begin{array}{l}\mathrm{MO} \\
\mathrm{OM}\end{array}$ & $\begin{array}{c}\mathrm{MM} \\
M M\end{array}$ & $\begin{array}{l}\mathrm{Ca} \\
D E\end{array}$ & $\mathrm{P}$ & $\begin{array}{c}\mathrm{ED} \\
\mathrm{kcal} / \mathrm{kg}\end{array}$ \\
\hline $\begin{array}{l}\text { Feno } \\
\text { Hay }\end{array}$ & 82,76 & 12,82 & 71,01 & - & 2,88 & 91,30 & 8,70 & 0,59 & 0,24 & $2.158^{1}$ \\
\hline $\begin{array}{l}\text { Bijú } \\
\text { DPS }^{2} \\
D S W\end{array}$ & $\begin{array}{l}83,68 \\
83,69\end{array}$ & $\begin{array}{l}24,27 \\
11,53\end{array}$ & $\begin{array}{l}22,49 \\
73,32\end{array}$ & $\begin{array}{l}10,40 \\
30,00\end{array}$ & $\begin{array}{l}7,95 \\
2,46\end{array}$ & $\begin{array}{l}85,33 \\
86,21\end{array}$ & $\begin{array}{l}14,67 \\
13,79\end{array}$ & $\begin{array}{l}0,34 \\
1,90\end{array}$ & $\begin{array}{l}0,32 \\
1,09\end{array}$ & $\begin{array}{l}2.882 \\
2.204\end{array}$ \\
\hline
\end{tabular}

1 NRC (1985).

2 DPS - Dejeto Peneirado Seco (DSW - Dry Sifted Wastes).

R. Bras. Zootec., v.32, n.6, p.1391-1396, 2003 
instalações. Nesta lavagem, saíram juntos os dejetos, a urina, os pêlos, os resíduos de ração, a água desperdiçada dos bebedouros e a água utilizada no processo de higienização. Esta técnica se baseou no transporte dos dejetos por meio da água corrente nas canaletas que estavam localizadas na parte inferior das baias. Os dejetos saíram das baias com a lavagem e foram para um tanque de estocagem, de onde foram sendo periodicamente retirados para a separação da parte sólida e líquida, por meio de um processo de peneiramento (peneiras vibratórias) e prensamento; posteriormente a parte sólida foi seca ao sol e moída e a fração líquida foi utilizada na irrigação de culturas da propriedade.

Os tratamentos utilizados foram: T1- Dieta controle; T2- Dieta com Bijú e T3- Dieta com DPS; sendo as dietas constituídas por feno de aveia, dejetos de suínos, fubá de milho, farelo de soja, farinha de carne e ossos, suplemento mineral e sal. Nas Tabelas 2 e 3, respectivamente, são apresentadas as composições percentuais e químicas das dietas utilizadas.

O confinamento teve duração de 75 dias, sendo 15 dias para a adaptação dos animais às instalações e ao alimento. Os alimentos fornecidos e as sobras

Tabela 2- Composição percentual das dietas Table 2 - Composition of the diets (\%)

\begin{tabular}{|c|c|c|c|}
\hline \multirow[b]{2}{*}{$\begin{array}{l}\text { Ingredientes } \\
\text { Ingredient }\end{array}$} & \multicolumn{3}{|c|}{$\begin{array}{l}\text { Dietas } \\
\text { Diets }\end{array}$} \\
\hline & $\begin{array}{l}\text { Controle } \\
\text { Control }\end{array}$ & $\begin{array}{l}\text { Bijú } \\
\text { Bijú }\end{array}$ & $\begin{array}{l}\text { DPS } \\
D S W\end{array}$ \\
\hline $\begin{array}{l}\text { Feno de aveia (\%) } \\
\text { Oat hay (\%) }\end{array}$ & 20,00 & 20,00 & 20,00 \\
\hline $\begin{array}{l}\text { Milho grão (\%) } \\
\text { Corn grain (\%) }\end{array}$ & 66,40 & 52,80 & 44,00 \\
\hline $\begin{array}{l}\text { Farelo de soja (\%) } \\
\text { Soybean meal (\%) }\end{array}$ & 10,40 & - & 8,80 \\
\hline $\begin{array}{l}\text { Farinha de carne e ossos (\%) } \\
\text { Meat and bone meal (\%) }\end{array}$ & 1,60 & 1,60 & 1,60 \\
\hline $\begin{array}{l}\text { Dejetos de suínos - Bijú (\%) } \\
\text { Swine wastes - Bijú (\%) }\end{array}$ & - & 24,00 & - \\
\hline $\begin{array}{l}\text { Dejetos de suínos - DPS }{ }^{2}(\%) \\
\text { Swine wastes - DSW }{ }^{2}(\%)\end{array}$ & - & - & 24,00 \\
\hline $\begin{array}{l}\text { Premix mineral }(\%)^{1} \\
\text { Premix mineral (\%) }\end{array}$ & 1,20 & 1,20 & 1,20 \\
\hline $\begin{array}{l}\text { Sal }(\%) \\
\text { Salt (\%) }\end{array}$ & 0,40 & 0,40 & 0,40 \\
\hline $\begin{array}{l}1 \text { Fosfato bicálcico (Dicalcium phosph } \\
29,98 \text {; sulfato de amônia (ammor } \\
\text { cobre (copper sulphate) } 1,00 \text {; sulfat } \\
\text { sulfato de cobalto (cobalt sulphate } \\
\text { (potassium iodate) } 0,02 \% \text {. } \\
2 \text { DPS - Dejeto Peneirado Seco (D. }\end{array}$ & $\begin{array}{l}\text { hate) } 49,9 \\
\text { nia sulfat } \\
\text { to de zin } \\
\text { e) } 0,05 \\
\text { sw - Dry }\end{array}$ & $\begin{array}{l}\text { calcár } \\
14,99 \\
\text { zinc si } \\
\text { dato }\end{array}$ & $\begin{array}{l}\text { nestone) } \\
\text { lfato de } \\
\text { e) } 3,99 \text {; } \\
\text { otássio }\end{array}$ \\
\hline
\end{tabular}

R. Bras. Zootec., v.32, n.6, p.1391-1396, 2003 foram submetidos a análises químicas de matéria seca (MS), proteína bruta (PB), fibra em detergente neutro (FDN), fibra em detergente ácido (FDA), extrato etéreo (EE), matéria orgânica (MO), matéria mineral (MM), cálcio (Ca), fósforo $(\mathrm{P})$ e energia digestível (ED), conforme metodologia descrita por Silva (1990). Já as pesagens dos cordeiros foram realizadas a cada 14 dias, sempre no mesmo horário e antes do fornecimento da ração. Foram medidos o ganho de peso diário (GP), a conversão alimentar (CA) e as ingestões de matéria seca (IMS), proteína bruta (IPB), fibra em detergente neutro (IFDN), extrato etéreo (IEE), cálcio (ICa) e fósforo (IP), sendo todos expressos em gramas por dia e por unidade de peso metabólico.

Como não existiam fêmeas da raça Bergamácia, o delineamento experimental utilizado foi o de blocos casualizados, utilizando-se a raça e o sexo como fator de homogeneização (blocagem) e teste de Tukey para a comparação das médias. Foram realizadas duas análises estatísticas separadas (3 x 2) - 3 tratamentos e 2 raças ou 2 sexo; sendo utilizada uma estrutura desbalanceada [ $\mathrm{n}=21$ (12 machos Santa Inês e 9 machos Bergamácia)] e balanceada [n = 24 (12 machos Santa Inês e 12 fêmeas Santa Inês)] para estimar os efeitos da raça e do sexo, respectivamente. As análises foram feitas utilizando-se o procedimento GLM e ANOVA, disponível no pacote computacional SAS (1997) para as análises envolvendo a raça e sexo, respectivamente.

\section{Resultados e Discussão}

O feno de aveia apresentou teores adequados de nutrientes (Tabela 1), mostrando ser um alimento de alto valor nutritivo e, assim, não influenciou negativamente os resultados dos tratamentos que continham dejetos. Os dois tipos de dejetos também apresentaram composição química rica em nutrientes, principalmente proteína, cálcio e fósforo. A diferença encontrada na concentração de nutrientes do Bijú e do DPS, possivelmente, deveu-se às diferenças no método de obtenção de cada um. Oliveira (1994) também relatou que a composição química dos dejetos é variável em função da diluição e do modo como são manuseados. As maiores diferenças entre os dois tipos de dejetos foram encontradas nos teores de PB, FDN, FDA, EE, Ca, P e ED.

O maior teor de proteína bruta $(24,27 \%)$ encontrado no dejeto tipo Bijú, provavelmente, foi devido à 
Tabela 3 - Teores de matéria seca (MS), proteína bruta (PB), fibra em detergente neutro (FDN), extrato etéreo (EE), matéria orgânica $(\mathrm{MO})$, matéria mineral $(\mathrm{MM})$, cálcio $(\mathrm{Ca})$, fósforo $(\mathrm{P})$ e energia digestível (ED) das dietas utilizadas

Table 3 - Contents of dry matter (DM), crude protein (CP), neutral detergent fiber (NDF), ether extract (EE), organic matter (OM), mineral matter (MM), calcium (Ca), phosphorus $(P)$ and digestible energy (DE) of the diets

\begin{tabular}{|c|c|c|c|c|c|c|c|c|c|}
\hline Item & $\begin{array}{c}\text { MS } \\
D M \\
\% \\
\end{array}$ & $\begin{array}{l}\mathrm{PB} \\
C P\end{array}$ & $\begin{array}{l}\text { FDN } \\
N D F\end{array}$ & $\begin{array}{l}\mathrm{EE} \\
E E\end{array}$ & $\begin{array}{l}\text { MO } \\
\text { OM }\end{array}$ & $\begin{array}{c}\text { MM } \\
M M\end{array}$ & $\mathrm{Ca}$ & $\mathrm{P}$ & $\begin{array}{c}\mathrm{ED} \\
D E \\
\mathrm{kcal} / \mathrm{kg}\end{array}$ \\
\hline $\begin{array}{l}\text { Controle } \\
\text { Control }\end{array}$ & 90,59 & 15,01 & 30,95 & 3,65 & 94,61 & 5,39 & 1,20 & 0,54 & 2.637 \\
\hline $\begin{array}{l}\text { Bijú } \\
\text { Bijú }\end{array}$ & 90,63 & 15,41 & 30,85 & 5,04 & 92,69 & 7,31 & 1,47 & 0,69 & 2.588 \\
\hline $\begin{array}{l}\mathrm{DPS}^{1} \\
\mathrm{DSW}^{1}\end{array}$ & 90,67 & 14,75 & 43,05 & 2,70 & 92,49 & 7,51 & 1,36 & 0,68 & 2.408 \\
\hline $\begin{array}{l}\text { Média } \\
\text { Average }\end{array}$ & 90,63 & 15,06 & 34,95 & 3,80 & 93,26 & 6,74 & 1,34 & 0,64 & 2.519 \\
\hline
\end{tabular}

1 DPS - Dejeto Peneirado Seco (DSW - Dry Sifted Wastes).

elevada quantidade de nitrogênio não protéico, vindo da urina dos suínos, já que esta não sofreu uma diluição com a água, como ocorreu no processo de obtenção do dejeto tipo DPS. Todavia os dois tipos de dejetos apresentaram valores de PB dentro das variações citadas por Hilliard et al. (1979), de 11,8 e 31,4\%. Lima et al. (1993) também encontraram valores semelhantes de PB (10,8\%) para dejetos de suínos peneirados.

Os dejetos também apresentaram elevados teores de cálcio e fósforo, sendo isto coerente ao descrito por Henning e Flachowsky (1982). Já os valores de energia digestível dos dejetos de suínos foram relativamente altos, quando comparados aos alimentos nobres, viabilizando a adição nas dietas dos ruminantes. Entretanto o Bijú apresentou melhores resultados, principalmente com relação aos teores de energia digestível e proteína bruta e já o DPS apresentou superioridade com relação aos teores de cálcio e fósforo.

Na Tabela 4 são apresentados os valores da ingestão média diária, em g/ $\mathrm{kg}^{0,75}$, de matéria seca (IMS) e valores médios diários de ganho de peso (GP) e conversão alimentar (CA), para os fatores dietas, raça e sexo. Não foram verificados efeitos das dietas e das raças sobre a IMS, mas os machos Santa Inês apresentaramse superiores a fêmeas Santa Inês $(P<0,01)$.

Houve influência das dietas sobre o GP dos animais $(\mathrm{P}<0,05)$, sendo que as dietas contendo dejetos de suínos proporcionaram ganhos inferiores às do controle. Segundo Craddock et al. (1974) dietas com alto nível protéico e baixo nível energético proporcionam menores taxas de crescimento, devido ao gasto protéico para se obter energia e ao gasto
Tabela 4 - Ingestão diária de matéria seca (IMS), ganho de peso (GP) e conversão alimentar (CA) para os fatores dietas, raça e sexo da raça Santa Inês

Table 4 - Daily intake of dry matter (DMI), weight gain (WG) and feed:gain ratio (F/G) for the factors diets, breed and sex of breed Santa Inês

\begin{tabular}{|c|c|c|c|}
\hline $\begin{array}{l}\text { Fatores } \\
\text { Factors }\end{array}$ & $\begin{array}{l}\text { g/kg0,75/dia) } \\
(\mathrm{g} / \mathrm{kg} \cdot 75 / \text { day })\end{array}$ & $\begin{array}{l}\text { WG (g/dia) } \\
\text { GP (g/day) }\end{array}$ & $\begin{array}{l}\text { CA } \\
F / G\end{array}$ \\
\hline \multicolumn{4}{|l|}{ Dietas $^{1}$ (Diets) } \\
\hline $\begin{array}{l}\text { T1- Controle } \\
\text { T1-Control }\end{array}$ & $68,4 a$ & 199a & $5,4 a$ \\
\hline $\begin{array}{l}\text { T2-Bijú } \\
\text { T2-Bijú }\end{array}$ & $65,0 \mathrm{a}$ & $162 b$ & $6,2 \mathrm{ab}$ \\
\hline $\begin{array}{l}\text { T3-DPS } \\
\text { T3- DSWa } \\
\text { Raças }^{2} \text { (Breeds) }\end{array}$ & $64,9 a$ & $158 b$ & 6,6b \\
\hline 3ergamácia & $68,5 \mathrm{~ns}$ & $196 *$ & $5,8 n s$ \\
\hline $\begin{array}{l}\text { Santa Inês } \\
\text { Sexo }^{2} \text { (Sex) }\end{array}$ & 65,3 & 165 & 6,2 \\
\hline $\begin{array}{l}\text { Macho Santa Inês } \\
\text { anta Inês male }\end{array}$ & $70,6 *$ & $205 *$ & $5,5 *$ \\
\hline $\begin{array}{l}\text { Fêmea Santa Inês } \\
\text { Santa Inês female }\end{array}$ & 59,2 & 125 & 6,9 \\
\hline \multicolumn{4}{|c|}{$\begin{array}{l}{ }^{1} \text { Médias seguidas de letras diferentes diferem entre si, na } \\
\text { coluna, pelo teste Tukey }(P<0,05) \text {. } \\
2 \text { ns, *: Médias não-significativas e significativas }(P<0,01) \text {, res- } \\
\text { pectivamente, na coluna pelo teste } F \text {. } \\
{ }^{1} \text { Averages followed by different letters in the column differ by Tukey test } \\
(P<.05) \text {. } \\
2 \text { ns, *: Averages no significant and significant }(P<.01) \text {, in the column by } \\
F \text { test. } \\
\text { a DPS - Dejeto Peneirado Seco (DSW - Dry Sifted Wastes). }\end{array}$} \\
\hline
\end{tabular}

energético para a eliminação do nitrogênio proveniente do catabolismo. Portanto, possivelmente este pior desempenho proporcionado pelas dietas com dejetos tenha ocorrido devido à diferença na concentração de energia das dietas. Entre as dietas com os diferentes tipos de dejetos não foram encontradas 
Tabela 5 - Ingestão média diária, em $\mathrm{g} / \mathrm{kg}^{0,75}$, de proteína bruta (IPB), fibra em detergente neutro (IFDN), extrato etéreo (IEE), cálcio (ICa) e fósforo (IP), para os fatores dietas, raças e sexos

Table 5 - Average daily intake, in $\mathrm{g} / \mathrm{kg} \cdot{ }^{75}$, of crude protein (ICP), neutral detergent fiber (INDF), ether extract (IEE), calcium (Ca) and phosphorus (IP), for the factor diets, breed and sexes

\begin{tabular}{|c|c|c|c|c|c|}
\hline $\begin{array}{l}\text { Fatores } \\
\text { Factors }\end{array}$ & $\begin{array}{l}\text { IPB } \\
\text { ICP }\end{array}$ & $\begin{array}{l}\text { IFDN } \\
\text { IND }\end{array}$ & $\begin{array}{l}\text { IEE } \\
\text { FIE }\end{array}$ & $\begin{array}{c}\mathrm{ICa} \\
F I C a\end{array}$ & $\begin{array}{l}\mathrm{IP} \\
\mathrm{IP}\end{array}$ \\
\hline $\begin{array}{l}\mathrm{g} / \mathrm{kg}^{0,75} / \mathrm{dia}(\mathrm{g} / \mathrm{kg} \\
\text { Dietas }^{1} \text { (Diets) } \\
\text { T1-Controle }\end{array}$ & & & & & \\
\hline T1-Control & $10,1 \mathrm{a}$ & $21,2 b$ & $2,5 b$ & $0,9 a$ & $0,3 b$ \\
\hline $\begin{array}{l}\text { T2 - Bijú } \\
\text { T3 - DPS a }\end{array}$ & $9,9 \mathrm{a}$ & $21,4 \mathrm{~b}$ & 3,3a & $0,9 \mathrm{a}$ & $0,4 a$ \\
\hline $\begin{array}{l}\text { T3 - DSW a } \\
\text { Raças }^{2} \text { - Breeds² }\end{array}$ & $9,4 a$ & $30,1 \mathrm{a}$ & $1,7 \mathrm{c}$ & $0,8 \mathrm{a}$ & $0,4 a$ \\
\hline Bergamácia & $10,2 \mathrm{~ns}$ & $24,8 \mathrm{~ns}$ & $2,6 \mathrm{~ns}$ & $0,9 \mathrm{~ns}$ & $0,4 \mathrm{~ns}$ \\
\hline $\begin{array}{l}\text { Santa Inês } \\
\text { Sexo }^{2} \text { - Sex } \\
\text { Macho Santa Inês }^{2}\end{array}$ & 9,6 & 24,3 & 2,4 & 0,8 & 0,4 \\
\hline $\begin{array}{l}\text { Male Santa Inês } \\
\text { Fêmea Santa Inês }\end{array}$ & $10,4^{*}$ & $26,0^{*}$ & $2,6^{*}$ & $0,9 *$ & $0,4^{*}$ \\
\hline Female Santa Inês & 8,8 & 22,0 & 2,3 & 0,8 & 0,3 \\
\hline
\end{tabular}

${ }_{1}^{1}$ Médias seguidas de letras diferentes diferem entre si, na coluna, pelo teste Tukey $(P<0,05)$.

2 ns, *: médias não significativas e significativas $(P<0,01)$, respectivamente, na coluna pelo teste $F$.

1 Averages followed by different letters in the column differ to each other by Tukey test $(P<.05)$.

2 ns, *: Averages no significant and significant $(P<.01)$, in the column, by $F$ test.

a DPS - Dejeto Peneirado Seco (DSW - Dry Sifted Wastes).

diferenças, sendo observada tendência de maiores ganhos para os animais que consumiram a dieta que continha o Bijú; talvez isso tenha ocorrido devido à maior quantidade de fibra da dieta com DPS, já que, segundo Manterola et al. (1987), aumento no teor de fibra da dieta leva à diminuição no consumo e no ganho de peso dos cordeiros.

O ganho de peso dos animais também foi diferente $(\mathrm{P}<0,01)$, entre as raças, sendo que a raça Bergamácia apresentou maior ganho de peso diário (196 g) que a raça Santa Inês (165 g). O valor obtido para os animais da raça Santa Inês foi semelhante ao encontrado por Arruda et al. (1981), que observaram ganho de peso diário de 164 g, em dieta à base de sabugo de milho.

Houve também influência do sexo, na raça Santa Inês $(\mathrm{P}<0,01)$ sobre o ganho de peso dos animais, como já era esperado, os machos foram superiores às fêmeas. O mesmo foi observado por Nunez et al., citados por Siqueira (1990), quando avaliaram o efeito do sexo e tipo de parto no ganho de peso de cordeiros.

Com relação à conversão alimentar não houve diferenças entre as raças; todavia, entre as dietas foram encontradas diferenças significativa $(P<0,05)$, sendo que os animais tiveram uma melhor CA quando consumiram a ração controle. No entanto, a dieta que continha Bijú não diferiu estatisticamente do controle e nem da dieta com DPS, o que pode ser devido ao mesmo fator já mencionado no caso do GP, ou seja, à concentração de energia. Os machos Santa Inês apresentaram as melhores CA $(\mathrm{P}<0,01)$.

São apresentados na Tabela 5 dados de ingestões de proteína bruta (IPB), fibra em detergente neutro (IFDN), extrato etéreo (IEE), cálcio (ICa) e fósforo (IP), para os fatores dietas, raças e sexos. Não foram encontradas diferenças entre as dietas para as ingestões de proteína bruta e cálcio. Para as demais ingestões houve diferenças significativas $(\mathrm{P}<0,05)$, sendo que a dieta com DPS proporcionou a maior ingestão de fibra em detergente neutro e a menor ingestão de gordura (EE).

Os animais que receberam a dieta com Bijú também consumiram mais gordura, comparativamente às dietas controle e DPS. No entanto não houve diferenças entre as dietas controle e com Bijú para o consumo de fibra em detergente neutro e entre as dietas com Bijú e com DPS para o consumo de fósforo. Possivelmente as diferenças encontradas nos consumos de nutrientes também devem-se as diferenças na composição química, que refletem o processo de obtenção do dejeto.

As raças não influenciaram nas ingestões de PB, FDN, EE, Ca e P; havendo no entanto, uma influência do sexo sobre estes consumos $(\mathrm{P}<0,01)$, sendo que os machos Santa Inês apresentaram as maiores ingestões. 


\section{Conclusões}

Os dois tipos de dejetos de suínos são diferentes em relação a sua composição química.

O produto denominado Bijú mostrou-se na composição química superior aos dejeto peneirado seco ao sol. Entretanto, estatisticamente, não foram encontradas diferenças nas condições do presente experimento. Dessa forma, o uso de um ou outro desses produtos fica dependente das relações econômicas na obtenção dos mesmos.

O uso de dejetos de suínos, como parte da dieta, proporciona resultados satisfatórios no desempenho de cordeiros terminados em confinamento.

Os cordeiros Bergamácia apresentaram ganhos de pesos superiores aos Santa Inês.

\section{Literatura Citada}

ARRUDA, F.A.V.; OLIVEIRA, E.R.; BARROS, N.N. et al. Restolho da cultura de milho para ovinos da raça Santa Inês mantidos em confinamento. In: REUNIÃO ANUAL DA SOCIEDADE BRASILEIRA DE ZOOTECNIA, 18., 1981, Goiânia. Anais... Goiânia: Sociedade Brasileira de Zootecnia, 1981. p.323.

CONFINAMENTO. A receita dos paulistas para engordar cordeiros. A Granja, n.542, p.12-17, 1993.

CRADDOCK, B.F.; FIELD, R.A; RILEY, M.L. Effect of protein and energy level on lamb carcass composition. Journal of Animal Science, v.39, n.2, p.325-330, 1974.

HENNING, A.; FLACHOWSKY, G. Pig excrement as a new feedstuff for ruminants. Pig News and Information, v.3, n.3, p.269-274, 1982.

HILLIARD, E.P.; BEARD, J.; PEARCE, G.R. Utilization of piggery waste I. The chemical composition and in vitro organic matter digestibility of pig feces from commercial piggeries in south eastern Australia. Agriculture and Environment, v.4, n.1, p.171-180, 1979.
LIMA, G.M.M.; OLIVEIRA, P.A.V.; GOMES, P.C. Determinação da digestibilidade aparente e do valor energético do esterco de suíno. In: CONGRESSO BRASILEIRO DE VETERINÁRIOS ESPECIALISTAS EM SUÍNOS, 6., Goiânia, 1993. Anais... Goiânia: EMBRAPA/CNPSA, 1993.

MANTEROLA, H.B.; MUÑOZ, S.M.S.; PEPE, N.S. et al. Desarrollo e un sistema intensivo de produccion de carne ovina en el secano semiarido de Chile. V. Efecto del nivel de fibra y del sistema de confinamiento sobre el comportamiento productivo de corderos destetados precozmente. Avances en Producción Animal, v.12, n.1-2, p.169-181, 1987.

MARTINS, V.R.A. Utilização de dejetos de suínos em dietas de ovinos em sistema de confinamento. Lavras: Universidade Federal de Lavras, 1997. p.51. Dissertação (Mestrado em Zootecnia) - Universidade Federal de Lavras, 1997.

NATIONAL RESEARCH COUNCIL - NRC. Nutrient requirements of sheep. 6.ed. Washington, D.C.: National Academy Press, 1985. 99p.

OLIVEIRA, P.A.V. Manual de manejo e utilização dos dejetos de suínos. Concórdia: EMBRAPA-CNPSA, 1993. p.188. (Documentos, 27)

OLIVEIRA, P.A.V. Impacto ambiental causado pelos dejetos de suínos. In: SIMPÓSIO LATINO AMERICANO DE NUTRIÇÃO DE SUÍNOS - CBNA, 3., São Paulo, 1994. Anais... São Paulo: EMBRAPA - CNPSA, p. 27-40, 1994.

SIQUEIRA, E.R. Estratégias de alimentação do rebanho e tópicos sobre produção de carne ovina. In: PRODUÇÃO DE OVINOS, Jaboticabal, 1990. Anais... Jaboticabal: FUNEP, 1990. p.157-171.

SILVA, D.J. Análise de alimentos (Métodos químicos e biológicos). Viçosa, MG: Universidade Federal de Viçosa, 1990. $160 \mathrm{p}$.

STATISTIC ANALYSIS SYSTEM - SAS. User's Guide. Version 6, 4.ed., v.1. Cary, NC: 1997. 890p.

Recebido em: 13/07/01

Aceito em: 08/10/02 